\title{
Intestinal Parasitosis and Their Associated Factors among People Living with HIV at University of Gondar Hospital, Northwest- Ethiopia
}

\author{
Tegegne Eshetu', Getinet Sibhatu', Mohammed Megiso', Abrham Abere ${ }^{3}$, \\ Habtamu Wondifraw Baynes ${ }^{2}$, Belete Biadgo ${ }^{2}$, Ayalew Jejaw Zeleke ${ }^{3 *}$
}

\author{
OPEN ACCESS \\ Citation: Tegegne Eshetu, Getinet \\ Sibhatu, Mohammed Megiso, Abrham \\ Abere $^{3}$, Habtamu Wondifraw Baynes ${ }^{2}$, \\ Belete Biadgo, Ayalew Jejaw Zeleke.. \\ Intestinal Parasitosis and Their \\ Associated Factors among People Living \\ with HIV at University of Gondar \\ Hospital, Northwest-Ethiopia. Ethioian J \\ Health Sci 2017;27(4):411. doi: \\ http://dx.doi.org/10.4314/ejhs.v27i4.12 \\ Received: February 16, 2017 \\ Accepted: February 24, 2017 \\ Published: July 1, 2017 \\ Copyright: () 2017 Tegegne Eshetu, et \\ al. This is an open access article \\ distributed under the terms of the \\ Creative Commons Attribution License, \\ which permits unrestricted use, \\ distribution, and reproduction in any \\ medium, provided the original author and \\ source are credited. \\ Funding: Nil \\ Competing Interests: The authors \\ declare that this manuscript was approved \\ by all authors in its form and that no \\ competing interest exists. \\ Affiliation and Correspondence: \\ ${ }^{1}$ Department of Quality Assurance, \\ School of Biomedical and Laboratory \\ Sciences, University of Gondar, \\ Ethiopia \\ ${ }^{2}$ Department of Clinical Chemistry, \\ School of Biomedical and \\ Laboratory Sciences, University of \\ Gondar, Ethiopia \\ ${ }^{3}$ Department of Parasitology, School \\ of Biomedical and Laboratory \\ Sciences, University of Gondar, \\ Ethiopia \\ "Email: ayalewjejaw@yahoo.com
}

\section{ABSTRACT}

BACKGROUND: Most HIV clients die of AIDS related intestinal parasitic infections rather than due to the HIV infection itself. Therefore, this study was aimed at determining the prevalence of intestinal parasite and their associated factors among HIV/AIDS clients at the University of Gondar Hospital, Northwest Ethiopia.

METHODS: Institution based cross sectional study was conducted using systematic random sampling technique from March to May 2016. A semi-structured questionnaire was used to collect data. Stool samples were collected and processed using direct wet mount, formol-ether concentration and modified Ziehl-Neelson staining techniques. Besides, blood samples were collected for CD4+ count estimation. Both descriptive and logistic regression analyses were used in data analysis. P-values $<0.05$ were considered as statistically significant.

RESULTS: A total of 223 participants were enrolled in this study, and the prevalence of intestinal parasitosis was found to be $29.1 \%$. The most predominant intestinal parasite detected was cyst of Entamoeba histolytica (8.5\%) followed by Ascaris lumbricoides (6.7\%), Strongyloides sterocoralis (3.6\%) and Cryptosporidium parvum (3.1\%), whereas Schistosoma mansoni (0.9\%) and Hymenolepis nana (0.9\%) were the least detected. Absence of toilet (AOR=19.4, CI: 6.46-58.3), improper hand washing before meal (AOR=11.23, 95\% CI: 4.16-30.27 and CD4+ count $<200$ cells $/ \mathrm{mm}^{3}$ (AOR=33.31, 95\% CI: 9.159-121.149) had significant association with prevalence of intestinal parasites.

CONCLUSION: The study indicated that intestinal parasites are still a problem among HIV/AIDS patients in the study area. Thus, routine examination for intestinal parasites and interventions should be carried out for better management of clients.

KEYWORDS: Intestinal Parasites, HIV/AIDS, associated factors, Gondar, Ethiopia 


\section{INTRODUCTION}

Epidemiological surveillance data shows that an estimated 2.1 million people are newly infected with Human Immunodeficiency Virus (HIV) and a total of 36.7 million people are living with HIV at the end of 2015. Moreover, it is also believed that an average of 1.1 million people die annually because of Acquired Immune Deficiency Syndrome (AIDS) worldwide (1). Intestinal parasitic infections are among the most common infections, and almost $80 \%$ of AIDS patients die of AIDS-related infections including such infections rather than of the HIV infection itself. This usually occurs late in the course of HIV infection when Cluster for Differentiation (CD4) $\mathrm{T}$-cell count has been severely depleted $(2,3)$.

Intestinal parasites could be opportunistic and non-opportunistic agents that cause diarrhea, which is a common presenting complaint in HIV infected individuals. The devastating effect of HIV on the CD4+ T-cells, coupled with intestinal parasites, will significantly affect patients since conditions of diarrhea will reduce Anti Retroviral Treatment and nutrient absorption (4). Although non-opportunistic parasites such as Entamoeba histolytica, Giardia lamblia, Trichuris trichiura, Ascaris lumbricoides and Ancyclostoma duodenal infect HIV/AIDS patients, opportunistic parasites play a major role in causing chronic diarrhea accompanied by weight loss $(5,6)$. Cryptosporidium parvum, Isospora belli, Cyclospora cyatinis and Microsporidium species are among the opportunistic protozoa associated with diarrhea in HIV/AIDS patients $(7,8)$. Strongyloides stercoralis, which is a nematode, can also causes diarrhea and overwhelming infestation in patients with immune suppressive disorders (4).

Although there has been an improvement in the survival of people living with HIV, there is still a considerable number of deaths related to AIDS across Ethiopia. Among HIV related health problems, intestinal parasitic infections pose a serious challenge with regard to reducing the morbidity and mortality of these people. Probably, intestinal parasites (IPs) are among the major life threatening infectious diseases among such individuals [Unpublished records]. Therefore, the aim of this study was to determine the prevalence of intestinal parasite and their predisposing factors among HIV/AIDS patients at the University of Gondar Hospital attending ART clinics in order to provide evidence based information, from which medical decisions can be taken.

\section{METHODS AND MATERIALS}

Study design, area and period: Institution based cross sectional study was conducted from March to May 2016 at University of Gondar Hospital. University of Gondar Hospital is a teaching referral hospital located $727 \mathrm{~km}$ far from Addis Ababa in the Northwest of Ethiopia. Gondar city has a latitude and longitude of $12^{0} 37^{\prime} \mathrm{N} 37^{0} 28{ }^{\circ} \mathrm{E}$ with an elevation of 2133 meter above sea level. The city is nicknamed "the Camelot of Africa" due to the presence of a group of royal castles. Based on figures from Central Statistics Agency (2007), Gondar has an estimated total population of 207,044 (9). University of Gondar Hospital is a referral hospital with more than 400 beds. It acts as the referral centre for four district hospitals in the area. It has a range of specialties including pediatrics, surgery, gynecology, psychiatry, HIV care and an outpatient's clinic. It serves a population of four million across the region. As a university hospital, it plays an important role in teaching medical and other health sciences students (10).

Study population, sample size and sampling procedure: The source population was all HIV positive individuals who came for ART care services at the hospital. The required sample size was calculated using single population proportion formula by considering $17.6 \%$ prevalence of intestinal parasites among HIV clients in Dessie, Ethiopia (11), 5\% desired precision and 95\% confidence interval (CI). This gave us a total sample size of 223 .

During participant selection, the previous four months patient flow data were reviewed for estimation. Then, the numbers of patients enrolled were allocated proportionally to each week according to the total number of clients proposed to be attended to during the study period. Depending on this analysis, approximate numbers

DOI: http://dx.doi.org/10.4314/ejhs.v27i4.12 
of participants who were expected to attend ART service during the three months of study period were determined. Finally, systematic random sampling was used to select study participants. Clients on anti-parasitic therapy or those who had been on it in the past two months were excluded from the study.

Data collection and processing: Data on demographic and behavioral information were collected through face-to-face interview using interviewer-administered questionnaire. Moreover, clients were provided with appropriate specimen container and applicator sticks to give sufficient amount of stool specimen. Parasite infections were diagnosed by examination of stool specimens examined as fresh wet mounts, Formol-ether concentration technique and Modified acid fast stain for detection of different stages of parasites. Blood samples were also collected in heparinated vacutainer tubes for CD4+ T-cell count; using a fully automated fluorescence activated cell sorting (FACS) counter in the ART Clinic of the hospital, Gondar, Ethiopia.

Data quality assurance: The questionnaires were checked for their consistencies and completeness by the investigators. The clients who participated in the study were informed about an appropriate sample collection. Special emphasis was given to diarrhea stool samples by giving priority. Inaddition, formed and semi-formed stool samples were preserved by formalin for further examination by microscope. Lastly, we performed internal quality control.

Data analysis and interpretation: Data was entered into Epi Info and imported into SPSS version 20 software for analysis. Logistic regression model was employed to assess the potential risk factors. The strength of associations was evaluated by odds ratios (OR) and 95\% confidence intervals (CI). Variables that showed co-linearity were omitted, whilst the remaining variables $\mathrm{P}<0.25$ in bivarate analysis were offered to multi-variable logistic regression. P-values $<0.05$ were considered as statistically significant.

Ethics approval and consent to participate: The study was conducted after ethical approval was obtained from the Institutional Ethical Review Committee of the University of Gondar Hospital. Following an explanation of the purpose, the benefits and the possible risks of the study, oral consent was obtained from each studied individual for participation. The interviews with study participants were conducted with strict privacy and confidentiality.

\section{RESULTS}

Socio-demographic and general characteristics of the study participants: A total of 223 individuals living with HIV/AIDS were recruited into this study. Among them, 99(44.4\%) were males and 124(55.6\%) were females. Most of the participants, $81(36.3 \%)$, were within the age group of 30-39 years with mean age of $31 \pm 4.5$. Out of the 223 study participants, $200(89.7 \%)$ had been on ART over different periods of time while 23(10.3\%) were not on ART. In terms of location of residence, the majority were urban dwellers: $193(86.5 \%)$ lived in urban areas and $30(14.5 \%)$ in rural areas (Table 1).

Prevalence of intestinal parasites: The overall prevalence of intestinal parasitosis was 65 (29.1\%). E.histoletica $19(8.5 \%)$ was the most predominant parasite detected followed by A.lumbricoides $15(6.7 \%)$ and S.sterocoralis $8(3.6 \%)$. On the other hand, S.mansoni and H.nana were the least detected parasites. Amazingly, equal prevalence of helminthes and protozoa was observed $(16.1 \%)$. The prevalence of opportunistic intestinal protozoan parasites were $5.8 \%$, and from these $3.1 \%$ was due to Cryptosporidium species followed by Cyclospora cyatinisis $2.7 \%$ (Table 2). As far as co-infection is concerned, single infection was identified in $86.1 \%(56 / 65)$ and the remaining $9(13.9 \%)$ had mixed infections. Three (33.33\%) of the confections were due to A.lumbricoides and E.histolytica/dipar (Table 3).

DOI: http://dx.doi.org/10.4314/ejhs.v27i4.12 
Table 1: Sociodemographic characteristics of the study participants at University of Gondar Hospital ART clinic, Northwest Ethiopia, 2016.

\begin{tabular}{|c|c|c|c|}
\hline Variables & & Frequency & Percent \\
\hline \multirow{4}{*}{ Gender } & Male & 99 & 44.4 \\
\hline & Female & 124 & 55.6 \\
\hline & $0-9$ & 8 & 3.6 \\
\hline & $10-19$ & 11 & 4.9 \\
\hline \multirow[t]{6}{*}{ Age in years } & $20-29$ & 42 & 18.8 \\
\hline & $30-39$ & 81 & 36.3 \\
\hline & $40-49$ & 57 & 25.6 \\
\hline & $50-59$ & 18 & 8.1 \\
\hline & $60-69$ & 5 & 2.2 \\
\hline & $>70$ & 1 & 0.4 \\
\hline \multirow{4}{*}{ Marital status } & Unmarried & 56 & 25.1 \\
\hline & Married & 110 & 49.3 \\
\hline & Widowed & 30 & 13.5 \\
\hline & Divorced & 27 & 12.1 \\
\hline \multirow[t]{7}{*}{ Educational status } & Illiterate & 30 & 13.5 \\
\hline & Primary (Grade 1-8) & 125 & 56.1 \\
\hline & Secondary (Grade 9-12) & 58 & 26 \\
\hline & Higher education & 10 & 4.5 \\
\hline & Civil servant & 20 & 9 \\
\hline & Private & 50 & 22.4 \\
\hline & Farmer & 22 & 9.9 \\
\hline \multirow[t]{5}{*}{ Occupational status } & Merchant & 53 & 23.8 \\
\hline & Student & 16 & 7.2 \\
\hline & Driver & 8 & 3.6 \\
\hline & Military & 7 & 3.1 \\
\hline & House worker & 47 & 21.1 \\
\hline \multirow[t]{3}{*}{ Income } & $<500$ & 17 & 7.6 \\
\hline & $500-100$ & 94 & 42.2 \\
\hline & $>1000$ & 112 & 50.2 \\
\hline \multirow[t]{2}{*}{ Residence } & Urban & 193 & 86.5 \\
\hline & Rural & 30 & 13.5 \\
\hline \multirow[t]{2}{*}{ ART status } & Yes & 200 & 89.7 \\
\hline & No & 23 & 10.3 \\
\hline
\end{tabular}

DOI: http://dx.doi.org/10.4314/ejhs.v27i4.12 
Table 2: prevalence of intestinal parasites among HIV/AIDS patients at University of Gondar hospital, 2016.

\begin{tabular}{llll}
\hline Intestinal parasites & & Frequency (n) & Percent (\%) \\
\hline Protozoan & & 36 & 16.1 \\
& & & \\
& Entoamoeba histolytica/dispar & 19 & 8.5 \\
& Cryptosporadium parvum & 7 & 3.1 \\
Cyclospora cyatinis & 6 & 2.7 \\
Helminthes & Giardia lamblia & 36 & 1.8 \\
& & 15 & 16.1 \\
& Ascaris lumbricoides & 8 & 6.7 \\
& Strongeloides sterocoralis & 3 & 3.6 \\
& Trichuris tricuria & 3 & 1.3 \\
& Hookworm & 3 & 1.3 \\
& Entobius vermicularis & 2 & 1.3 \\
& Schistosoma mansoni & 2 & 0.9 \\
Oyer all prevalence & Hyminolopis nana & 65 & 0.9 \\
& & 29.1 \\
\hline
\end{tabular}

Table 3: prevalence of multiple intestinal parasites among HIV/AIDS patients at university of Gondar hospital, 2016).

\begin{tabular}{lll}
\hline Intestinal parasites & Frequency & Percent \\
\hline A.lumbricoid \& E.histolytica/dipar & 3 & 33.33 \\
A.lumbricoid \& S.sterocoralis & 2 & 0.9 \\
A.lumbricoid \& G.lamblia & 1 & 0.4 \\
& & \\
S.sterocoralis \& E.histolytica/dispar & 1 & 0.4 \\
Hookworm \& E.histolytica/dispar & 1 & 0.4 \\
S.sterocoralis \& H.nana & 1 & 0.4 \\
\hline
\end{tabular}

Prevalence of intestinal parasitic infections based on clinical status: The prevalence of intestinal parasitic infections was higher on preART 39.1\%(9/23) participants than on those who were on ART 28\% (56/200). However, there was no significant association $(\mathrm{p}=0.332)$ between the overall infection rate and ART status. On the other hand, parasitosis status with respect to the CD4+ T-cell count was variable among the study participants, and there was statistically significant association $(\mathrm{p}<0.001)$ between CD4+ T-cell count and the overall parasite prevalence rate among the study participants. High prevalence of intestinal parasitic infections, $73.1 \%$ (49/67), was observed in study participants with CD4+ T-cell count of $<200$ cells/ul, whereas the parasitic infection was found to be $8.6 \%(5 / 58)$ in clients with a CD4+ T- cell count of $>500$ cells/ul. The majority, $(71.2 \%)$, of the study participants with acute/chronic diarrhea were infected by at least one of any intestinal parasites. The distribution of any intestinal parasitic infection in relation to ART, CD4 T-cell count and diarrheal status is presented in Table 4. Factors Associated with intestinal parasite: Washing hands before eating food, latrine availability and CD4 level were found to be significantly associated with the prevalence of intestinal parasitosis. Accordingly, individuals who did not wash their hands before eating food were about 18 times more likely to be intestinal parasitosis positive compared to their counter parts (AOR=17.765, 95\% CI: 5.780, 54.606). Latrine availability was also found to be independently associated with the outcome variable studied.

DOI: http://dx.doi.org/10.4314/ejhs.v27i4.12 
Those respondents who did not have latrine were 6.205 times at higher risk of being IP positive than respondents who had access for latrine $(\mathrm{AOR}=6.205,95 \%$ CI: $1.745,22.063)($ Table 5$)$.

Table 4: Prevalence of intestinal parasitic infections based on clinical status in HIV/AIDS patients at University of Gondar Hospital, 2016.

\begin{tabular}{lllll}
\hline Characteristics & \multicolumn{2}{l}{ Intestinal parasitosis } & Chi-square & \multirow{2}{*}{ P-value } \\
\cline { 2 - 3 } & \multicolumn{2}{l}{ Yes } & No & \\
\hline ART status & $56(28 \%)$ & $144(72 \%)$ & 1.232 & 0.332 \\
$\quad \begin{array}{l}\text { On-ART } \\
\text { Pre-ART }\end{array}$ & $9(39.1 \%)$ & $14(60.9 \%)$ & & \\
CD4 status & & & \\
$\quad<200$ & $49(73.1 \%)$ & $18(26.9 \%)$ & & \\
$200-499$ & $11(11.2 \%)$ & $87(88.8)$ & & \\
$\quad>500$ & $5(8.6 \%)$ & $53(91.4 \%)$ & & $<0.001$ \\
Acute/Chronic Diarrhea & & & \\
$\quad$ Yes & $42(71.2 \%)$ & $59(28.8 \%)$ & & \\
$\quad$ No & $23(23.2 \%)$ & $99(76.8 \%)$ & & \\
\hline
\end{tabular}

Table 5: Multi-variable analysis of factors associated with intestinal parasitosis among HIV/AIDS patients at University of Gondar Hospital, 2016.

\begin{tabular}{|c|c|c|c|c|}
\hline \multirow[b]{2}{*}{ Variable } & \multicolumn{2}{|c|}{ Intestinal Parasitosis } & \multirow[b]{2}{*}{ COR, $95 \% \mathrm{CI}$} & \multirow[b]{2}{*}{$\mathrm{AOR}, 95 \% \mathrm{CI}$} \\
\hline & $\begin{array}{ll}\text { Yes, } & \mathrm{n} \\
(\%) & \end{array}$ & No & & \\
\hline \multicolumn{5}{|l|}{ Income } \\
\hline$<500$ & $1(94.1)$ & $16(5.9)$ & $.163(.021,1.284)$ & $.074(.001,4.449)$ \\
\hline $500-1000$ & $33(35.1)$ & $61(64.9)$ & $1.414(.782,2.556)$ & $.810(.302,2.176)$ \\
\hline$>1000$ & $31(27.7)$ & $81(72.3)$ & 1 & 1 \\
\hline Washing $\quad h$ & & & & \\
\hline \multicolumn{5}{|c|}{ before eating foods } \\
\hline Yes & $22(12.9)$ & $148(87.1)$ & 1 & 1 \\
\hline No & $43(81.1)$ & $10(18.9)$ & $28.927(12.728,65.745)$ & $17.765(5.780,54.606)^{*}$ \\
\hline \multicolumn{5}{|c|}{ Latrine availability } \\
\hline Yes & $31(17.1)$ & $150(82.9)$ & 1 & 1 \\
\hline No & $34(81)$ & $8(19)$ & $20.565(8.686,48.685)$ & $6.205(1.745,22.063)^{*}$ \\
\hline \multicolumn{5}{|l|}{ CD4 cell count/ul } \\
\hline$<200$ & $49(73.1)$ & $18(26.9)$ & $39.472(14.696,106.020)$ & $33.311(9.159,121.149 *)$ \\
\hline $200-499$ & $6(6.5)$ & $87(93.5)$ & 1 & 1 \\
\hline$>500$ & $10(15.9)$ & $53(84.1)$ & $2.736(.940,7.962)$ & $3.286(.868,12.440)$ \\
\hline
\end{tabular}

DOI: http://dx.doi.org/10.4314/ejhs.v27i4.12 


\section{DISCUSSION}

This study showed that the prevalence of intestinal parasites among HIV/AIDS clients was found to be $29.1 \%$. This is comparable with studies done in Dessie $(28.3 \%)$ and in India $(32.5 \%)(11,12)$. However, it is lower compared to studies conducted in Cameron (59.5\%) and Addis Ababa $(37.8 \%)$ and Yirgalem (35.8\%) (13-15). On the other hand, it is higher compared to a previous report from Nigeria (11.4\%) (16). These prevalence variations might be due to geographic difference of study population, study methodologies and presence or absence of better followup and better awareness of patients themselves in adopting treatment and prevention against intestinal parasites. As far as the diversity of parasite species is concerned, several (eleven) types of intestinal parasites were detected, seven of which were helminthes and the remaining four were protozoan parasites. Similar to the previous findings reported from other parts of Ethiopia $(17,18)$, E.histolytica was the most frequently detected parasite $(8.5 \%)$ in this study. A.lumbricoides was the second $(6.7 \%)$ most abundant parasite. This finding is in agreement with the study conducted in Dessie Referral Hospital which showed that A.lumbricoides was the second most predominant species (11). The presence of soil transmitted helminthes like A.lumbericoides and others in this study indicated that HIV infected individuals may fasten the progression of AIDS due to down regulation of the immune system (19).

Importantly, opportunistic intestinal parasites (Cryptosporadium parvum, Cyclospora cyatinenis and strongloides stercoralis) were identified in the study participants. The prevalence of S.stercoralis infection in thi study is lower than the previous findings in Ethiopia: $12 \%$ in Yirgalem (20), $7.8 \%$ in Jimma (21), and $10.7 \%$ in Bahirdar (near to the study area) (22). This may pinpoint better interventions were being carried out in the study area. However, its prevalence $(3.6 \%)$ in this study shall not be overlooked and needs special emphasis for further reduction because of its devastating effect on HIV patients and other immune suppressed people. It is accountable for about $60-85 \%$ mortality rate in immune compromised persons. Among such individuals, it may result in hyper infection syndrome due to internal auto infection. Involving such type of infection may result in a devastating condition by serving the larvae as mechanical vectors for different microbial organisms. i.e. juveniles of the parasite can carry and transport intestinal bacteria to the circulation and disseminate to different parts of the body (brain, lung, peritoneum, etc) which may ultimately end with sever health outcomes or death $(23,24)$. The prevalence of other two opportunistic intestinal coccidian parasites is also considerable as they may result in prolonged diarrhea that can reduce antiretroviral treatment and nutrient absorption among HIV/AIDS (4). Moreover, this study found that the presence of acute or chronic diarrhea was statistically associated with the prevalence of intestinal parasitosis in the study population. Many scholars also identified that Intestinal parasitic infections (IPIs) are the most common organisms that result in diarrhea in HIV infected individuals $(4,25)$. Thus, detection of these opportunistic and other parasites among a significant number of HIV infected individuals in this study revealed that people living with HIV/AIDS in the study area are at high risk of developing life threatening conditions.

Northwest Ethiopia is known for high prevalence S.mansoni of (26-28). However, this study reported that its prevalence is unusual and low $(0.9 \%)$. This may be related with the site of residence of the participants since majority were urban dwellers, $193(86.5 \%)$. This is due to the fact that most previous studies were done in the rural parts of Northwest Ethiopia where people usually use streams, ponds, rivers and other natural water sources for washing and domestic water consumption. Thus, the likelihood of S.mansoni transmission in rural dwellers is higher compared to urban residents that frequently use pipe water for their daily requirements.

The prevalence of intestinal parasites among pre-ART clients was (39.1\%), but a decreased rate (28\%) among clients with ART adherents was observed. It is in line with that of the studies reported from Dessie (39\%), Gondar (43.5\%) and

DOI: http://dx.doi.org/10.4314/ejhs.v27i4.12 
Cameroon $(40.5 \%)(11,29,30)$. Reduction of parasitosis among HIV clients who begun ART followup may indicate the success of intervention efforts in reducing the significance number of opportunistic and other intestinal parasitic infections in the specified high risk group.

This study also tried to describe some proven and hypothesized associated factors and showed an indiscriminate prevalence of intestinal parasitic infection among study participants by age category, sex, level of education, occupation, residence and others. However, it revealed that unavailability of latrine, CD4 status and not washing hands before eating food had statistically significant associations with intestinal parasitosis. Accordingly, individuals who did not have access to latrine in their home or vicinity were 6.2 times more likely to get infected with intestinal parasitosis. Different studies also reported that prevalence of IPIs is associated with unavailability of latrine (31). This is due to the fact that failure to access latrine results in open defecation and environmental contamination. Thus, it facilitates the likelihood transmission of IPIs.

Similarly, improper washing of hands before meal was found to be a determinant factor for intestinal parasitic infections. In view of that participants who did not not always practice washing hands before meal were about 18 times (AOR $=17.765,95 \%$ CI: 5.780, 54.606) more likely to be infected by intestinal parasites than those who always practiced it. This shows the role of education in preventing IPIs and keeping personal hygiene practices.

Inaddition, this study indicated that IPIs were found significantly associated with participants having $<200$ cells/ul count compared to clients with any of CD4 categories. For instance, having $<200 \mathrm{cell} / \mathrm{mm}^{3}$ count were 33.31 times more likely to be infected by the parasites than those who were with the range of 200 and 400 level (AOR $=33.31,95 \%$ CI: 9.159, 121.149). Similarly, a previous report from elsewhere in the world suggested that increased frequencies of intestinal parasites were observed in individuals with CD4+ T-cell count $<200$ cells/ $\mu 1$ (12). This may be due to the fact that opportunistic parasites are known to resolve spontaneously with immune restoration among HIV/AIDS patients $(8,32)$. The association of these parasites for lower 200 cells/mm3 CD4 count is comparable with studies done in other parts of Ethiopia (Dessie, Addis Ababa, Hawasa) $(11,18,33)$.

Although this study contributes a piece of information, as its strong side, about HIV/AIDS and intestinal parasitosis to the already existing knowledge, it was only a cross sectional design which might not show temporal relationships and thus the observed associations may not necessarily be causal. In conclusion, intestinal parasitic infections had not gone away and they are still common health problems among HIV positive patients in the study area. Personal hygiene, indiscriminate defecation/not using toilet, and CD4 count $<200$ cell/ul were variables which showed significant association with intestinal parasitosis. Therefore, early detection and treatment of the parasitic infection, giving health education regarding these parasites are important to reduce parasitic infection of peoples living with HIV.

\section{ACKNOWLEDGEMENTS}

We wish to acknowledge the University of Gondar for the financial support of the study. We also acknowledge the priceless support given by all who participated in the study, especially the study participants and data collectors.

\section{REFERENCES}

1. WHO, http://www.who.int/mediacentre/factsheets/fs3 60/en/. HIV/AIDS Fact sheet Updated November 2016

2. World Health Organization (WHO). Provisional WHO clinical case study of Intestinal parasites in AIDS patients. Weekly Epidemiological Record, 2002 ; (10): 303306

3. Shah U, Purohit B, Chandralekha D, Mapara M. Co-infection with Cryptosporidium, Isospora and $\mathrm{S}$. stercoralis in a patient with AIDS: a case report. Indian Journal of Medical Microbiology. 2003; $\quad$ (21):137138. 
4. Smith P, Lane H, Gill V, Manischewitz J, Quinnan G, Fauci, A. Intestinal infectionsin patients with the acquired immunodeficiency syndrome (AIDS). Etiology and response to therapy. Annals of Internal Medicine.1998 ; (108): 328-333.

5. Lucas S. Missing infections in AIDS. Transactions of the Royal Society Tropical Medicine and Hygiene. 1990;84 (Suppl 1):3438.

6. Hammouda N, Sadaka H, El-Gebaly W, ElNassery S. Opportunistic intestinal protozoa in chronic diarrheic immune suppressed patients. Journal of Egyptian Society of Parasitology.1996 ; (26):143-153.

7. Assefa S, Erko B, Medhin G, Assefa Z, Shimelis T. Intestinal parasitic infections in relation to HIV/AIDS status, diarrhoea and CD4 T-cell count. BMC Infectious Disease. 2009 ; (9): 155.

8. Adamu H. and Petros B. Intestinal protozoan infections among HIV positive persons with and without Antiretroviral Treatment (ART) in selected ART centers in Adama, Afar and Dire-Dawa, Ethiopia. Ethiopian Journal of Health Development. 2009; (23):133-140.

9. The 2007 Population and Housing Census of Ethiopia: Statistical Report for Amhara Region.

http://www.etharc.org/index.php/resources/do wnload/view.download/68/383. accessed date, $1 / 6 / 2017$.

10. Information about Gondar Hospital, http://www2.le.ac.uk/institution/gondarinformation-hub/medical-electives/gondarhospital, accessed date, 1/6/2017.

11. Missaye A, Dagnew M, Alemu A, Alemu A. Prevalence of intestinal parasites and associated risk factors among HIV/AIDS patients with pre-ART and on-ART attending dessie hospital ART clinic, Northeast Ethiopia. AIDS Research and Therapy. 2013; 10:7.

12. Khalil S, Ranjan B, Sinha S, Panda A, Singh $\mathrm{Y}$, Joseph A, et al. Intestinal Parasitosis in Relation to Anti-Retroviral Therapy, CD4+ Tcell Count and Diarrhea in HIV Patients. Korean J Parasitol.2015; 53(6): 705-712.
13. Nkenfou CN, Nana CT, Payne VK. Intestinal Parasitic Infections in HIV Infected and NonInfected Patients in a Low HIV Prevalence Region, WestCameroon. PLoS ONE. 2013; 8(2): e57914.

14. Mihiretie H, Taye B , Tsegaye A. Intestinal Parasitosis in Relation to CD4+T Cells Levels and Anemia among HAART Initiated and HAART Naive Pediatric HIV Patients in a Model ART Center in Addis Ababa, Ethiopia. PLoS ONE.2015; 10(2): e0117715.

15. Shimelis T, Tassachew Y, Lambiyo T. Cryptosporidium and other intestinal parasitic infections among HIV patients in southern Ethiopia: significance of improved HIVrelated care. Parasites \& Vectors. 2016; 9:270.

16. Feyisayo E, Tinuade E, Hamisu A, Akwen $\mathrm{H}$, Torpey K. Prevalence of intestinal parasites among HIV/AIDS patients attending Infectious Disease Hospital Kano, Nigeria. Pan African Medical Journal. 2014; 17:295.

17. Moges F, Kebede Y, Kassu A, Degu G, Tiruneh M, Gedefaw M. Infection with HIV and intestinal parasites among street dwellers in Gondar city, northwest Ethiopia. Jpn $J$ Infect Dis. 2006; 59:400-3.

18. Mengist HM, Taye B, Tsegaye A. Intestinal Parasitosis in Relation to CD4+T Cells Levels and Anemia among HAART Initiated and HAART Naive Pediatric HIV Patients in a Model ART Center in Addis Ababa, Ethiopia. PLoS ONE.2015; 10(2): e0117715.

19. Borkow G , Bentwich Z. Chronic Immune Activation Associated with Chronic Helminthic and Human Immunodeficiency Virus Infections: Role of Hyporesponsiveness and Anergy. Clinical Microbiology Reviews, 2004; 17(4): 1012-1030.

20. Getaneh A, Medhin G, Shimelis T. Cryptosporidium and Strongyloides stercoralis infections among people with and without HIV infection and efficiency of diagnostic methods for Strongyloides in Yirgalem Hospital, southern Ethiopia. BMC Res Notes. 2010; 3:90.

21. Awole M, Gebre-Selassie S, Kassa T, Kibru G. Prevalence of intestinal parasites in HIV-

DOI: http://dx.doi.org/10.4314/ejhs.v27i4.12 
infected adult patients in South Western Ethiopia. Ethiop J Health Dev. 2003; 17:71-8.

22. Alemu A, Shiferaw Y, Getnet G, Yalew A, Addis Z. Opportunistic and other intestinal parasites among HIV/AIDS patients attending Gambi Higher Clinic in Bahirdar City, North West Ethiopia. Asian Pac J Trop Med. 2011; 4:661-5

23. Siddiqui AA, Berk SL. Diagnosis of Strongyloides stercoralis infection. Clin Infect Dis. 2001;33(7):1040-7.

24. Evering T, Weiss LM. The immunology of parasite infections in immune compromised hosts. Parasite Immunol.2006; 28:549-65.

25. Assefa S, Erko B, Medhin G, Assefa Z, ShimelisT. Intestinal parasitic infections in relation to HIV/AIDS status, diarrhea and CD4 T-cell count. BMC Infectious Diseases, 2009; 9:155 doi: 10.1186/1471-2334-9-155.

26. Mathewos B, Alemu A, Woldeyohannes $\mathrm{D}$, Alemu A, Addis Z, Tiruneh $\mathrm{M}$, et al. Current status of soil transmitted helminths and Schistosoma mansoni infection among children in two primary schools in North Gondar, Northwest Ethiopia: a cross sectional study. BMC Research Notes.2014; 7:88.

27. Alemu A, Tegegne Y, Damte D, Melku M. Schistosoma mansoni and soil-transmitted helminths among preschool-aged children in Chuahit, Dembia district, Northwest Ethiopia: prevalence, intensity of infection and associated risk factors. BMC Public Health.2016; 16:422.
28. Worku L, Damte D, Endris M, Tesfa H, Aemero M. Schistosoma mansoni infection and associated determinant factors among school children in Sanja Town,Northwest Ethiopia. Journal of Parasitology Research. 2014; $2014: 7$.

29. Telele NF, Damte DG, Selassie S. Intestinal parasitic infections among HIV seropositives and seronegatives adult patients presented with diarrhea in Gondar, North west Ethiopia. Revi Ant Infec Dis. 2010; 3:7-8.

30. Sarfati C, Bourgeois A, Menotti J, Liegeois F, Moyou-Somo R, Delaporte E, et al. Prevalence of intestinal parasites including microsporidia in human immunodeficiency virus-infected adults in Cameroon: a crosssectional study. AmJTrop Med Hyg. 2006; 74(Suppl 1):162-164.

31. Babatunde SK, Salami AK, Fabiyi JP AgbedeOo, DesaluluOo. Prevalence of intestinal parasitic infection in $\mathrm{HIV} / \mathrm{sero}$ positive patients in llorin,Nigeria, Kanem journal of medical sciences. 2008; 2(2):37-40.

32. Gurunathan S. Habib R. Baglyos L. Meric C. Plotkin S. Dodet B. Corey L. Tartaglia J. Use of predictive markers of HIV disease progression vaccinetrials. Vaccine Journal. 2009; (27):1997-2015.

33. Shimelis T, Tassachew $\mathrm{Y}$ and Lambiyo $\mathrm{T}$. Cryptosporidium and other intestinal parasitic infections among HIV patients in southern Ethiopia: significance of improved HIVrelated care. Parasites \& Vectors.2016; 9:270. 